\title{
Article \\ Stability Assessment of Rock Mass System under Multiple Adjacent Structures
}

\author{
Bo Sung Kim and Joon Kyu Lee *
}

check for

updates

Citation: Kim, B.S.; Lee, J.K. Stability Assessment of Rock Mass System under Multiple Adjacent Structures. Systems 2022, 10, 5 . https://doi.org/ 10.3390 /systems 10010005

Academic Editor: Vladimír Bureš

Received: 22 November 2021

Accepted: 29 December 2021

Published: 1 January 2022

Publisher's Note: MDPI stays neutral with regard to jurisdictional claims in published maps and institutional affiliations.

Copyright: (C) 2022 by the authors. Licensee MDPI, Basel, Switzerland. This article is an open access article distributed under the terms and conditions of the Creative Commons Attribution (CC BY) license (https:// creativecommons.org/licenses/by/ $4.0 /)$.
Department of Civil Engineering, University of Seoul, Seoul 02504, Korea; kbs7774@uos.ac.kr
* Correspondence: jkleegeo@uos.ac.kr

Abstract: Numerical modeling is important for exploring the fundamental processes occurring in rock and for evaluating the real performance of structures built on and in rock mass system, and thus for supporting the design of rock engineering problems. Estimating the stability of rock mass foundation systems entirely based on a theoretical approach is a complicated task if there exists overlapping of their potential collapse modes. This paper applies finite element limit analysis to evaluate the bearing capacity of equally spaced multiple strip footings resting on rock mass obeying the modified non-linear Hoek-Brown failure criterion. Numerical solutions are expressed in terms of the efficiency factor that is dependent on the spacing between footings, as well as the rock mass properties. In addition, the effects of surface surcharge and footing roughness are quantified. The maximum spacing at which the interfering effect of adjacent footings becomes disappeared is evaluated and an algebraic expression for approximating the maximum spacing is proposed. Failure mechanisms for a few cases of rock mass under multiple strip footings are examined.

Keywords: rock mass system; stability; structures; interference; efficiency factor

\section{Introduction}

Rock differs from most other engineering materials in that it contains fractures of one type or another which render its structure discontinuous. Hence, a clear distinction must be made between the intact rock and the rock mass [1]. The intact rock refers to the unfractured blocks between discontinuities comprised of rock-forming minerals. The rock mass is the in situ medium consisting of intact rock blocks separated by discontinuities, such as bedding plane, faults, joints, and folds, and often has in inhomogeneous and anisotropic properties. Numerous classification systems of intact rock and rock mass have been developed and the overview of the classification systems is given in [2].

As shown in Figure 1, the properties of the rock mass are significantly dependent on the problem domain, When the domain enlarges to a certain volume, called representative elementary volume (REV), the rock properties will reach a steady magnitude [3]. In other words, the rock properties become constant at some REV if the discontinuity existence is statistically homogeneous in the domain considered. The rock properties may further oscillations in the trace if the discontinuity existence is heterogeneous. Thus, numerical stress analysis consists of discontinuous method for sub-REV scale and continuum method for large volume of rock mass.

In engineering practice, it is necessary to place footings so close to each other or to build them adjacent to another structures. Especially, multiple equally spaced footings are encountered in the form of railway sleepers and grillage foundations [4-6]. From the available literature for a group of multiple footings, it is revealed that the ultimate bearing capacity of interfering footings is always greater than that of single isolated footings due to the overlapping of their failure surface. The different investigations were based on small scale model test [7,8], field plate load test [9], stress characteristic method [7], finite element method [10,11], lower bound limit analysis [12], and upper bound limit analysis [13,14]. 


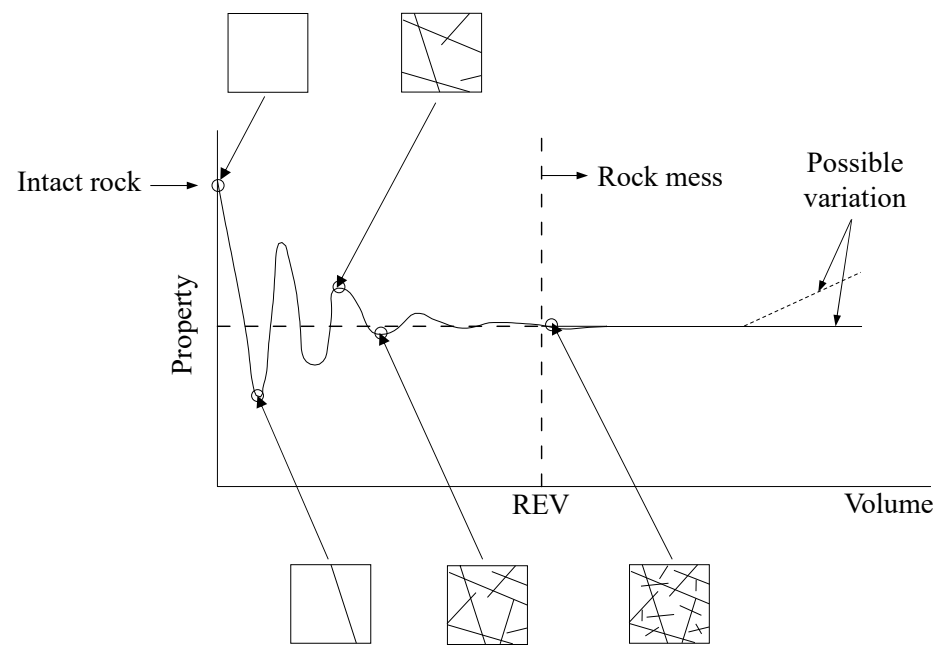

Figure 1. The concept of representative element volume (REV) for rock mass system (modified from [3]).

All existing studies mentioned above are concerned with multiple strip footings on soils following Mohr-Coulomb failure criterion. However, these solutions have some limitations in determining the bearing capacity of rock masses with joints and fractures. Additionally, the linear Mohr-Coulomb failure criterion may not capture the nonlinear failure behavior of rock mass [15,16]. Alternatively, a non-linear failure criterion proposed by Hoek and Brown [17] is considered for the ultimate bearing capacity of footings over rock mass, although only limited studies on the interfering effect of rock footings were reported. Javid et al. [18] estimated the bearing capacity of two closely spaced strip footings using the distinct element method. More recently, Shamloo and Imani [19] evaluated the bearing capacity of two neighboring strip footings based on the upper bound limit analysis.

In this study, the vertical bearing capacity of a group of multiple strip footings, identically spaced and equally loaded to failure simultaneously, is computed with the finite element limit analysis. The modified Hoek-Brown non-linear failure criterion is used for intact rock or heavily jointed rock mass. The obtained results are compared with the existing solutions and the bearing capacity calculations are presented as a function of spacing between the footings, rock mass properties, footing roughness, and surface surcharge. Collapse mechanisms of rock mass under multiple closely spaced footings are broadly discussed.

\section{Background}

The numerical methods commonly used for predicting the response of rock mass are presented in Figure 2. The method selection depends on system geometry and problem domain. The numerical analysis consists of discontinuous method for sub-REV scale and continuum method for large volume of rock mass.

To estimate the non-linear strength envelope of intact rock and jointed rock masses, the original Hoek-Brown (HB) failure criterion was proposed in 1980 and has been subsequently updated. The last version, used here, is expressed as [20]

$$
\sigma_{1}^{\prime}=\sigma_{3}^{\prime}+\sigma_{c i}^{\prime}\left(m_{b} \frac{\sigma_{3}^{\prime}}{\sigma_{c i}^{\prime}}+s\right)^{a}
$$

where $\sigma_{c i}$ is the uniaxial compressive strength of the intact rock. $\sigma_{1}$ and $\sigma_{3}$ are the major and minor principal stresses, respectively, which are considered as positive when tensile in nature. $m_{b}, s$, and $a$ are the dimensionless material parameters, defined as

$$
m_{b}=m_{i} \exp \left(\frac{G S I-100}{28-14 D}\right)
$$




$$
\begin{gathered}
s=\exp \left(\frac{G S I-100}{9-3 D}\right) \\
a=\frac{1}{2}+\frac{1}{6}\left(e^{-G S I / 15}-e^{-20 / 3}\right)
\end{gathered}
$$

where $m_{i}$ is the value of $m_{b}$ for intact rock. The value of $m_{i}$ is related to the minerology and texture of the intact rock, varying from 4 for very fine weak rock (e.g., claystone) to 33 for coarse igneous light-colored rocks (e.g., granite). The value of $m_{i}$ can be obtained from experiments. GSI is the geological strength index which features the quality of the rock mass [21]. The value of GSI ranges from about 10 for extremely poor rock masses to 100 for intact rock. $D$ is the disturbance factor which depends on the extent of weathering and blast damage of the rock mass. The value of $D$ varies from 0 for the undisturbed in situ rock masses to 1 form extremely disturbed rock masses. The modified HB criterion is applicable to intact rock or heavy jointed rock mass that can be considered is isotropic and homogeneous and therefore is proper to estimate the bearing capacity of surface footings on rock.

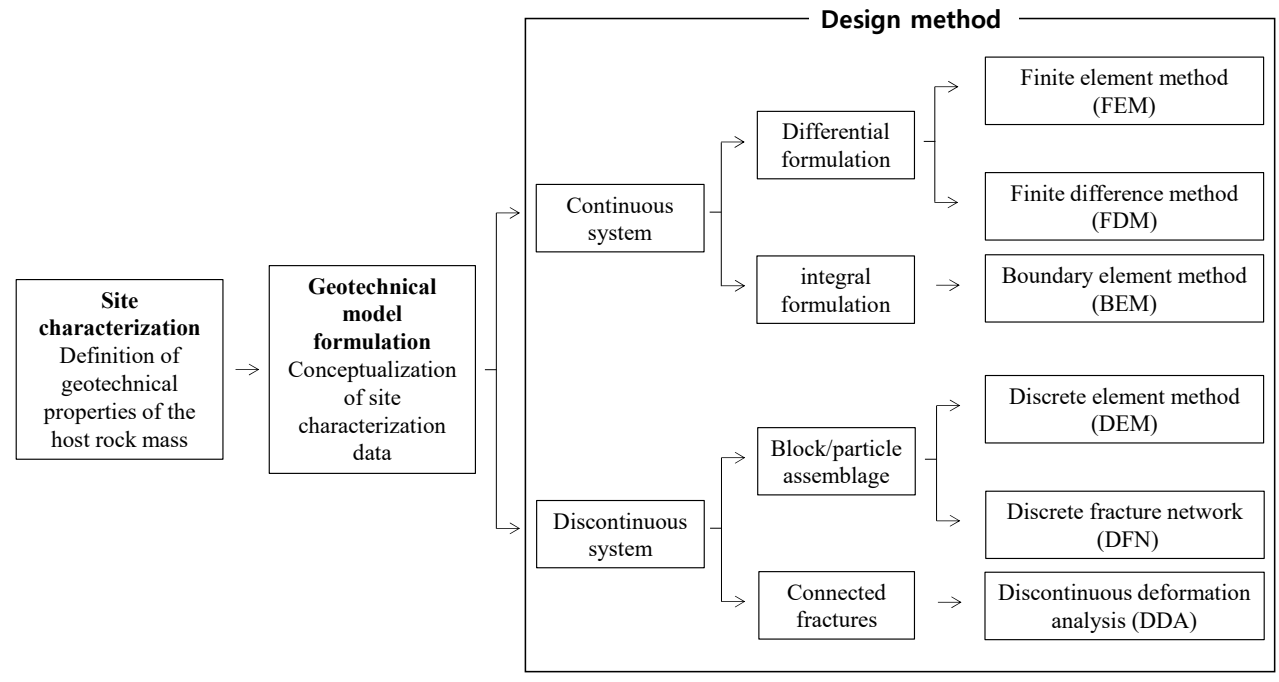

Figure 2. Design process of engineering problem for rock mass with an emphasis on numerical methods.

The ultimate bearing capacity of a strip footing subjected to vertical loading is expressed as

$$
q_{u}=\sigma_{c i} N_{\sigma}
$$

where $N_{\sigma}$ is the bearing capacity factor, which is related to the HB material parameters, namely, $m_{i}, G S I$, and $D$. However, the value of $\sigma_{c i}$ is very little effect on the footing capacity $[16,18]$.

\section{Problem Statement}

Figure 3 illustrates the geometry and parameters of the rock-footing system considered. A number of multiple strip rigid footings rest upon a rock medium with horizontal ground surface. The footings are having width $B$ and are placed at equal clear spacing $S$. The interfering effect of multiple footings is quantified by the adjacent spacing ratio $S / B$, which ranges from 0.1 to 6 . The base of the footing is considered as the perfectly smooth and perfectly rough providing upper and lower limits of capacity for multiple footings with given material properties. The rock mass obeys the Hoek-Brown failure criterion as a function of $\sigma_{c i}, m_{i}, G S I$, and $D$. The $\sigma_{c i}$ value is kept equal to $20 \mathrm{MPa}$ [22] and the $m_{i}$ values are taken as $7,10,15,17$, and 25 for five types of rocks [23]. The values of GSI and $D$ are within the range of 10 to 90 and 0 to 1 , respectively. The rock mass has unit weight $\gamma$, which is quantified by $\sigma_{c i} / \gamma B$. The value of $\sigma_{c i} / \gamma B$ varies from 125 to $\infty$ that indicates the weightless rock mass [24]. The ground is loaded with a uniform surcharge pressure $q$ and its effect is represented by $q / \sigma_{c i}$. The value of $q / \sigma_{c i}$ ranges between 0 to 1 , which cover most 
problems of practical interest [25]. The vertical downward load is simultaneously applied to the center of each footing and all footings are collapsed exactly at the identical bearing load $Q_{u}$.

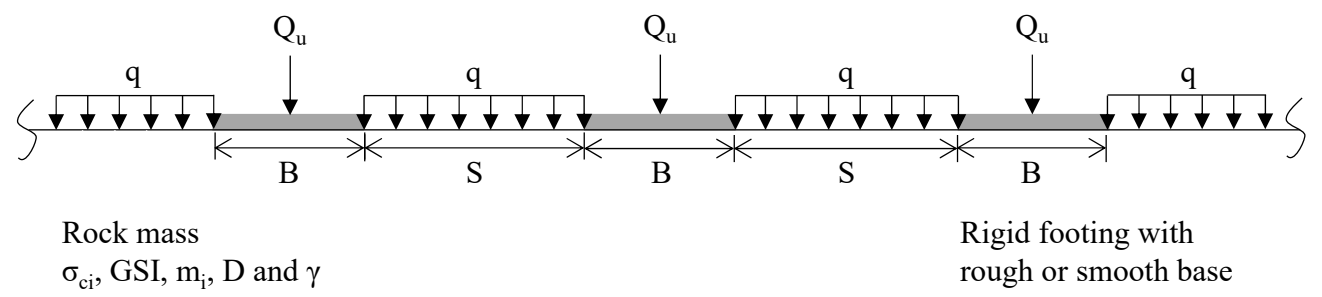

Figure 3. Problem definition.

To compare the bearing capacity of an interfering strip footing with that of a single isolated footing, the efficiency factor $\xi$ is introduced:

$$
\xi=\frac{N_{\sigma(m u l)}}{N_{\sigma(i s o)}}
$$

where $N_{\sigma(m u l)}$ is the bearing capacity factor for an interfering footing in a group of multiple footings and $N_{\sigma(i s o)}$ is the bearing capacity factor for single isolated footing with the same width of the interfering footing. From this, the ultimate bearing capacity of an intervening footing is determined using the following expression:

$$
q_{u}=\sigma_{c i} N_{\sigma(i s o)} \xi
$$

\section{Finite Element Limit Analysis}

In finite element limit analysis (FELA), the following assumptions are made: the material is rigid perfectly plastic, obeys an associated flow rule and calculations based on this theory only apply for small deformations. Furthermore, rigorous lower bound (LB) and upper bounds (UB) which bracket the true solution can only be obtained in FELA with the correct element types. The LB solution aims for the lower bound of the ultimate load in the static admissible stress field, while the UB solution considers that there exists an upper bound of the true bearing capacity based on the kinematically allowable velocity field [26]. In the presents study, FELA were carried out by using the commercially available software Optum G2 [27]. All numerical results from presents study are described by using an average $(\mathrm{AVG})$ solution:

$$
\mathrm{AVG}=(U B+L B) / 2
$$

Figure 4 shows that the problem domain and the stress boundary conditions. The footing is adopted as a weightless and perfectly rigid element and only vertical displacement applies. To achieve a perfectly smooth and perfectly rough interface between the rock mass and footing, the interface factors is set as 0 and 1 . Owing to a symmetrical nature of the problem about a vertical line passing through the center of the multiple footing, only quarter of the problem is considered in the computations. The horizontal boundary was placed S/2 away from the center of multiple footings and the vertical boundary was placed at a depth of $12 B$ from the surface to avoid boundary effects. The vertical boundaries were modeled fixed horizontally, and the bottom boundary was modeled as fully fixed horizontally and vertically. The footing and rock mass were discretized into either 6-noded triangular elements in UB analysis or 3-noded triangular elements in LB analysis. An automatically adaptive mesh refinement was used for all analyses, and a total of 10,000 upper bound and lower bound elements were used in three adaptive steps. In addition, 5000 elements were used in the initial mesh stage. 


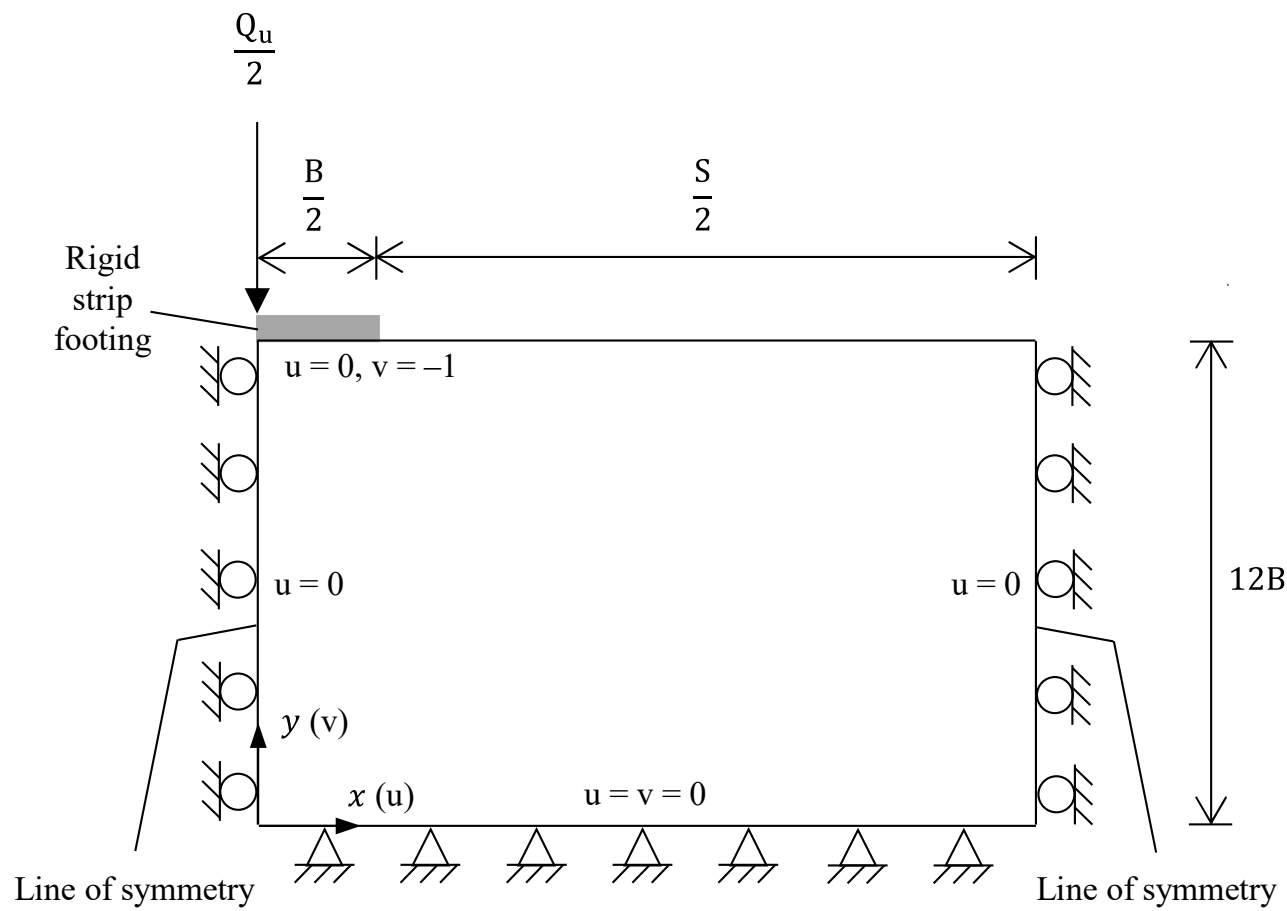

Figure 4. Problem domain and boundary conditions.

\section{Results and Comparison}

To validate the results of the present study on strip footings for weightless rock mass with different GSI and $m_{i}$, a comparison of bearing capacity $N_{\sigma 0}$ obtained in this study with the analyses of Serrano et al. [28] using the slip line method, Merifield et al. [24] using the finite element limit analysis, Chakraborty and Kumar [29] using lower bound finite element limit analysis, and Keshavarz and Kumar [25] using the stress characteristics method. A comparative representation of all these values is given in Table 1 . The present results remain very close to the existing solutions. Additionally, the values of $N_{\sigma 0}$ for isolated foundation with rough and smooth roughness for $G S I=50, m_{i}=20$ are determined to be 1.722 and 1.709 , respectively, which are $1.2 \%$ and $3.0 \%$ in error compared with those from Keshavarz and Kumar [25].

Table 1. Comparisons of $N_{\sigma 0}$ values obtained from this study and literature for single isolated strip footings on rock mass.

\begin{tabular}{ccccccc}
\hline GSI & $\boldsymbol{m}_{\boldsymbol{i}}$ & SE & ME & CK & KK & This Study \\
\hline 10 & 10 & 0.072 & 0.077 & 0.075 & 0.077 & 0.075 \\
& 20 & 0.159 & 0.156 & 0.151 & 0.153 & 0.151 \\
& 30 & 0.259 & 0.238 & 0.230 & 0.237 & 0.226 \\
\hline 30 & 10 & 0.393 & 0.397 & 0.388 & 0.393 & 0.390 \\
& 20 & 0.716 & 0.713 & 0.701 & 0.702 & 0.685 \\
& 30 & 1.038 & 0.988 & 1.015 & 1.007 & 0.960 \\
\hline 50 & 10 & 1.031 & 1.037 & 1.028 & 1.025 & 1.024 \\
& 20 & 1.760 & 1.765 & 1.739 & 1.742 & 1.722 \\
& 30 & 2.458 & 2.367 & 2.406 & 2.426 & 2.366 \\
\hline 70 & 10 & 2.434 & 2.444 & 2.415 & 2.415 & 2.437 \\
& 20 & 3.998 & 4.012 & 3.978 & 3.961 & 3.904 \\
& 30 & 5.470 & 5.491 & 5.437 & 5.417 & 5.389 \\
\hline 90 & 10 & 5.741 & 5.758 & 5.724 & 5.689 & 5.683 \\
& 20 & 9.100 & 9.125 & 9.086 & 9.015 & 9.015 \\
& 30 & 12.237 & 12.270 & 12.198 & 12.114 & 12.085 \\
\hline
\end{tabular}

Note: SE = Serrano et al. (2000)—stress characteristics method; ME = Merifield et al. (2006)—finite element limit analysis; CK = Chakraborty and Kumar (2015) -lower bound finite element limit analysis; KK = Keshavarz and Kumar (2017)—stress characteristics method. 
Figure 5 provides the obtained $q_{u}$ value of two interfering footings $(S / B=1)$ on rock mass, together with other numerical analysis for same footing and soil conditions. The Figure 5 shows the variation of $q_{u}$ values with GSI for the case of $m_{i}=7$ and 10 . As shown in the Figure 5, the results of the numerical analysis are very close to those obtained with distinct element method of Javid et al. [18]. However, the value of $q_{u}$ in upper bound solutions by Shamloo et al. [19] was under-predicted, and the difference increases with increasing GSI. Given that the result of present study is included in the result of Javid et al. [15] and Shamloo et al. [19], it can be seen that agree well with previous study.
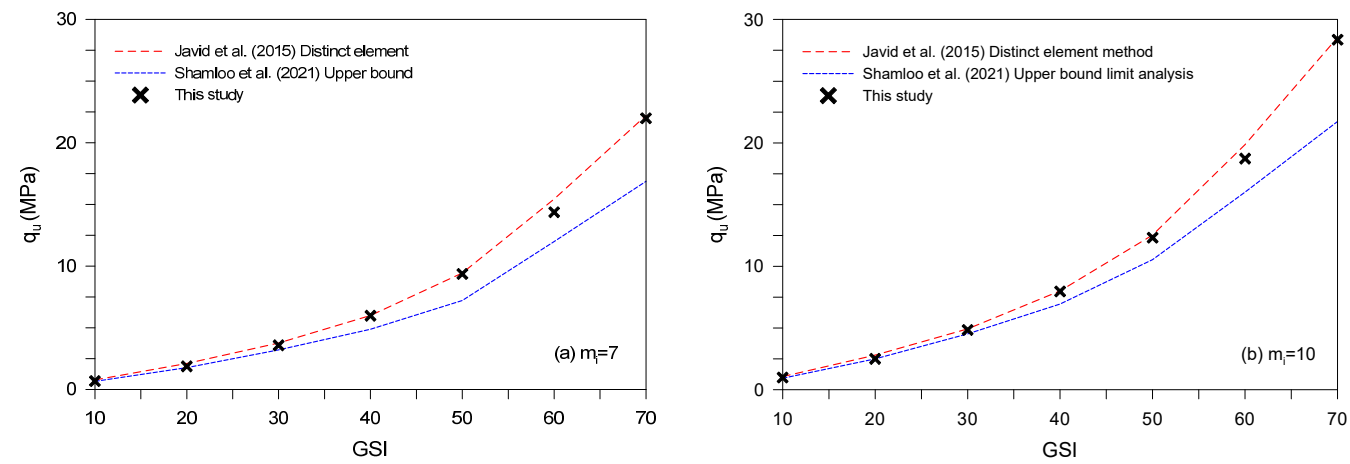

Figure 5. Comparison of $q_{u}$ of two interfering footingsith $S / B=1$ for $q=0, \sigma_{c i}=10 \mathrm{MPa}$ and $D=0$ : (a) $m_{i}=7$; and (b) $m_{i}=10$.

The variation of the efficiency factors $\xi$ for different combinations of $S / B$ and GSI is shown in Figure 6 for the case of $D=0, \sigma_{c i} / \gamma B=$ infinite, $q / \sigma_{c i}=0$ and $m_{i}=7,15$, and 25 . Figure 6 shows that the $\xi$ value decreases as $S / B$ increases. It is important to note that the lower GSI, the greater $\xi$ value, however the greater rate at which $\xi$ values decreases as adjacent space increases. Furthermore, as $m_{i}$ increases, the $\xi$ values according to each GSI increases in the same adjacent space. All $\xi$ values decrease as $S / B$ increases, reached value of 1 . In the case of $\xi=1$, the bearing capacity of multiple footing has no adjacent distance influence, meaning that the behavior of isolated footing is performed. In the present study, the space ratio corresponding to $\xi=1$ is defined as $S_{\max } / B$. $S_{\max } / B$ varies depending on GSI and $m_{i}$, respectively, and details of this are illustrated in Figure 7.
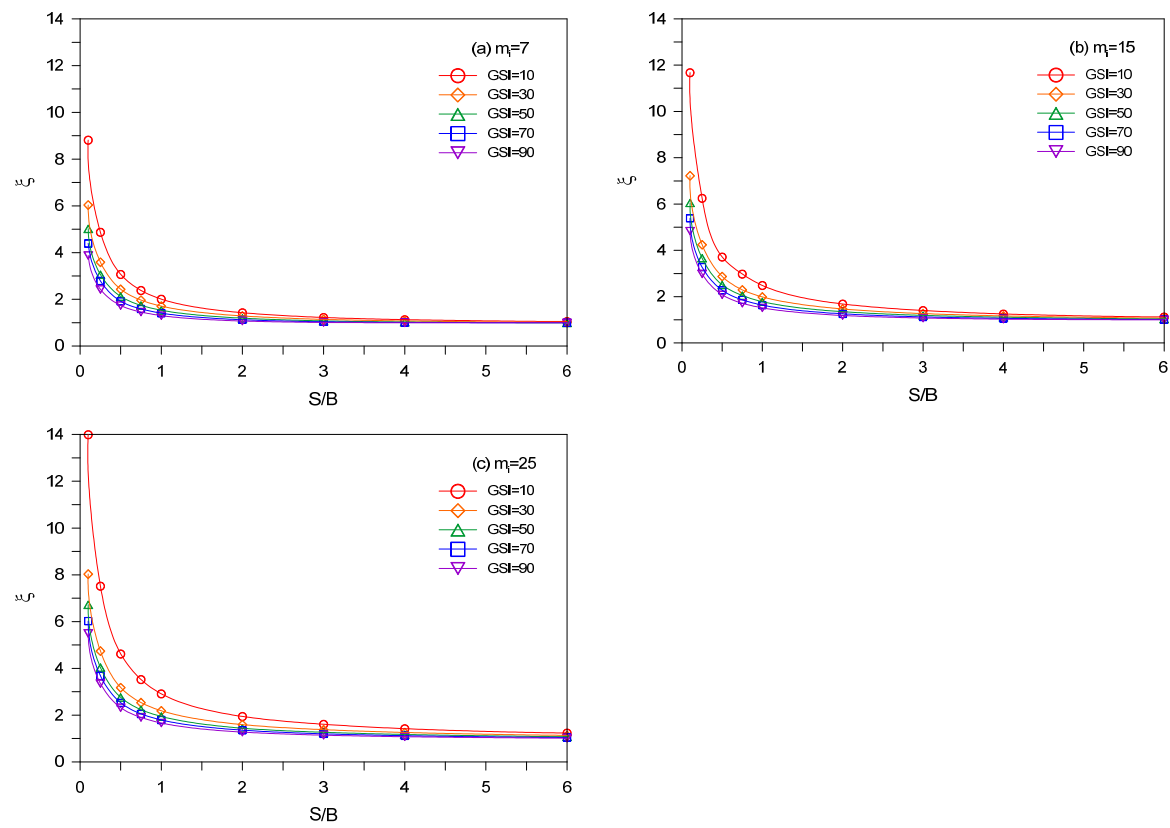

Figure 6. Variation of $\xi$ with $S / B$ and GSI for $D=0, \sigma_{c i} / \gamma B=\infty$ and $q / \sigma_{c i}=0$ : (a) $m_{i}=7$; (b) $m_{i}=15$; and (c) $m_{i}=25$. 


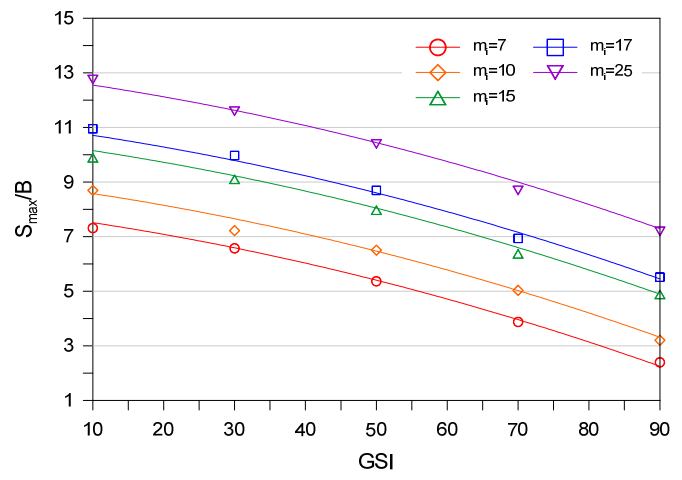

Figure 7. Variation of $S_{\max } / B$ with GSI and mi for multiple strip footings with $D=0, \sigma_{c i} / \gamma B=\infty$ and $q / \sigma_{c i}=0$.

The variation of $S_{\max } / B$ for different combinations GSI and $m_{i}$ is shown in Figure 7 for the case of $D=0, \sigma_{c i} / \gamma B=$ infinite, $q / \sigma_{c i}=0$. Figure 7 shows that $S_{\max } / B$ decreases with increasing GSI, but for a given GSI, $S_{\max } / B$ increases with increasing $m_{i}$. It should be noted that the maximum value of $S_{\max } / B$ is 12.76 for $G S I=10, m_{i}=25$ and the minimum value of $S_{\max } / B$ is 2.41 for $G S I=90, m_{i}=7$. In addition, the $S_{\max } / B$ can be described as exponential function of GSI. Expressed in terms of the $S_{\max } / B$ :

$$
S_{\max } / B=a-3.9 \exp (0.01 \mathrm{GSI})
$$

where $a$ is the coefficients for the parameters of $m_{i}$. As stated in Equation (9), it is obvious that the value of $S_{\max } / B$ for multiple footings on rock mass drops towards decreases with increasing of GSI. It is worth noting that these coefficients are accurate for interpolation only, and should not be used for extrapolation beyond $10<G S I<90$. The relations of a with $m_{i}$ have the form of $\left(\mathrm{R}^{2}=0.991\right.$ and $\mathrm{R}^{2}=0.997$, respectively $)$

$$
a=9+0.441 m_{i}-0.005 m_{i}^{2}
$$

The proposed expressions of Equations (9) and (10) provide a satisfactory fit and good prediction.

The variation of the efficiency factor $\xi$ for different combinations of $S / B$ and $D$ is shown in Figure 8 for the case of $m_{i}=10, \sigma_{c i} / \gamma B=$ infinite, $q / \sigma_{c i}=0$ and $G S I=10,50$, and 90. Figure 8 shows that the value of $\xi$ decreases as $D$ increases. It can also be seen that as GSI increases, the value of $\xi$ decreases and this trend increases as $D$ decreases.

The variation of the efficiency factors $\xi$ for different combinations of $S / B$ and $\sigma_{c i} / \gamma B$ is shown in Figure 9 for the case of $m_{i}=10, D=0, q / \sigma_{c i}=0$ and $G S I=10,50$, and 90. Figure 9 shows that the greater $\sigma_{c i} / \gamma B$ for a given value of $\sigma_{c i} / \gamma B$, the greater the value of $\xi$. However, it should be noted that the smaller GSI, the significant the difference in the value of $\xi$ according to $\sigma_{c i} / \gamma B$, but the greater GSI, the smaller the difference in the value of $\xi$. This indicated that for the case of $G S I=90$, the unit weight of rock mass has little effect on the value of $\xi$ of multiple footings. In addition, as GSI decreases, the efficiency factor of $\sigma_{c i} / \gamma B$ except 125 decreases. For the case of $\sigma_{c i} / \gamma B=125$, the value of $\xi$ increases slightly when GSI increases from 10 to 50 , but when it is greater than 50 , the value of $\xi$ decreases. 

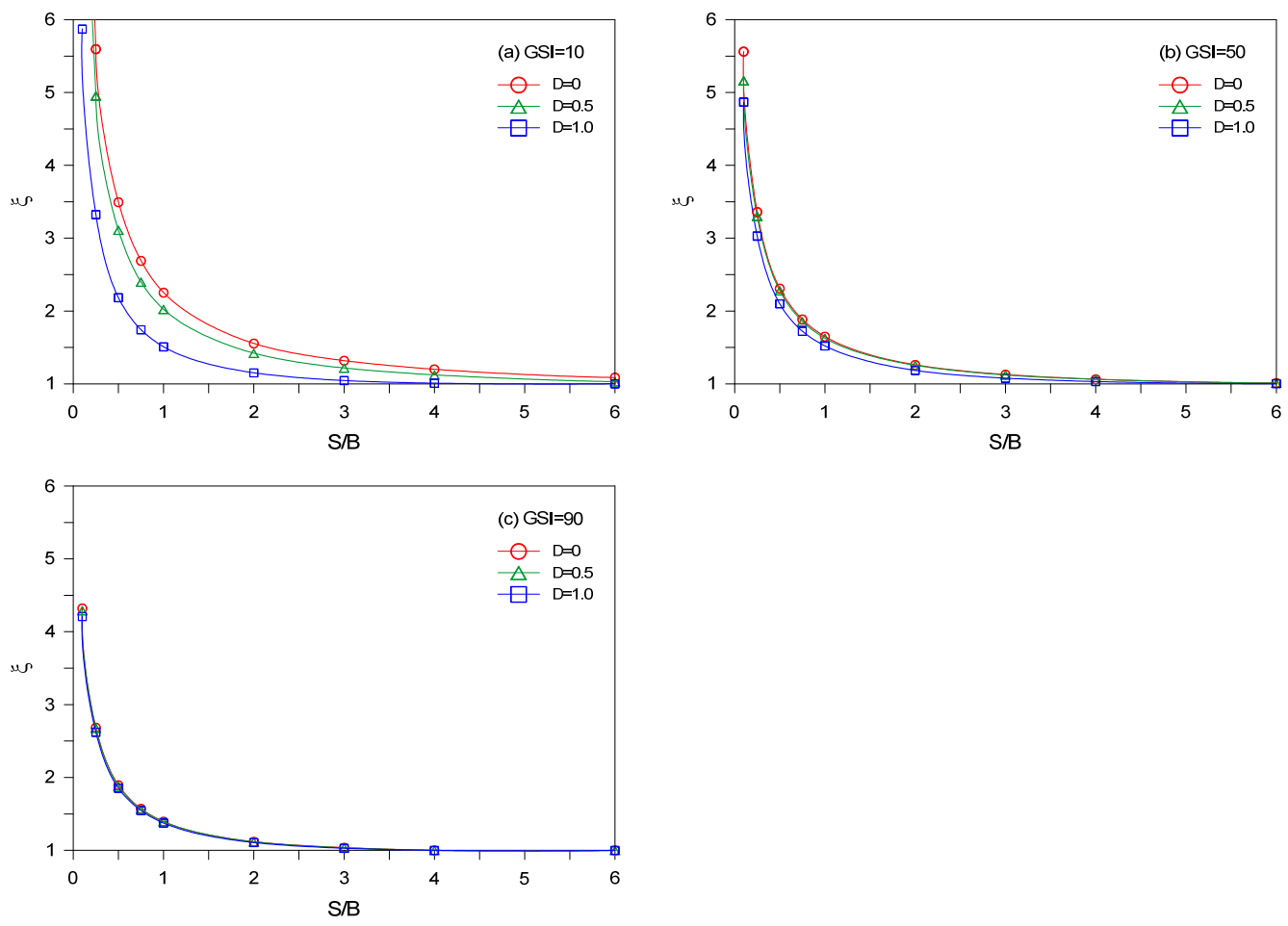

Figure 8. Variation of $\xi$ with $S / B$ and $D$ for $m_{i}=10, \sigma_{c i} / \gamma B=\infty$ and $q / \sigma_{c i}=0$ : (a) $G S I=10$; (b) GSI = 50; and (c) $G S I=90$.
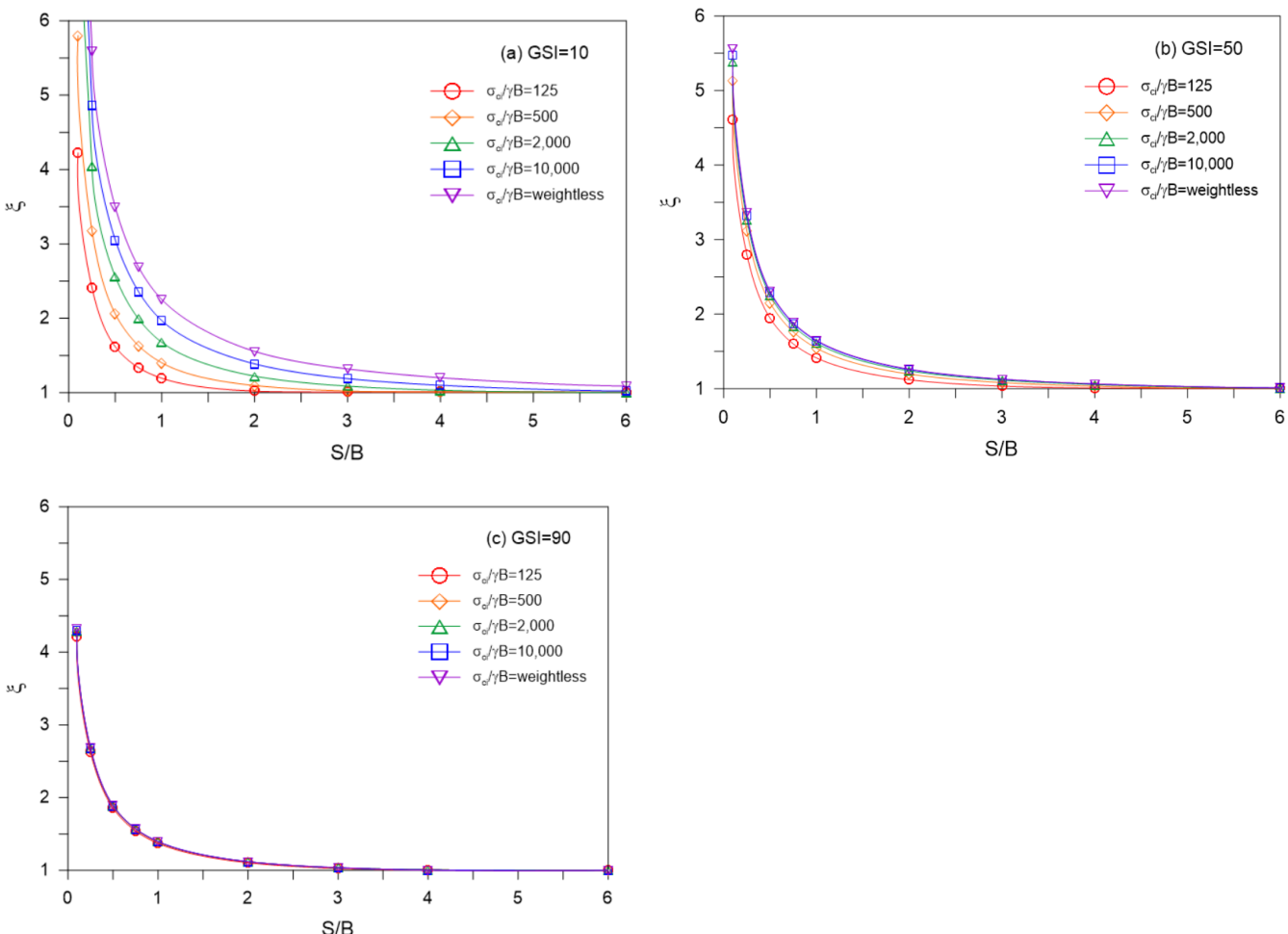

Figure 9. Variation of $\xi$ with $S / B$ and $\sigma_{c i} / \gamma B$ for $m_{i}=10, D=0$ and $q / \sigma_{c i}=0$ : (a) $G S I=10$; (b) $G S I=50$; and (c) $G S I=90$.

The variation of the efficiency factor $\xi$ for different combinations of $S / B$ and $q / \sigma_{\mathrm{ci}}$ is shown in Figure 10 for the case of $m_{i}=10, D=0, \sigma_{c i} / \gamma B=$ infinite and $G S I=10,50$, and 90. Figure 10 shows that decrease in the value of $\xi$ when surcharges are applied. Given that the value of $\xi$ resulting from the applied of surcharge is smaller than the value of $\xi$ 
in the without of surcharge, this implies that surcharge reduces the value of $\xi$. As the GSI increases, the $\xi$ values continues to decrease for $q / \sigma_{c i}=0$ and 0.001 , while for $q / \sigma_{c i}=0.1$ and 1.0 , the $\xi$ values increases. For the case of $q / \sigma_{c i}=0.01$, the $\xi$ values varies slightly with the change in GSI. It should also be noted that increasing GSI from 10 to 50 increases $\xi$ values, however decreasing $\xi$ value from 50 to 90 .
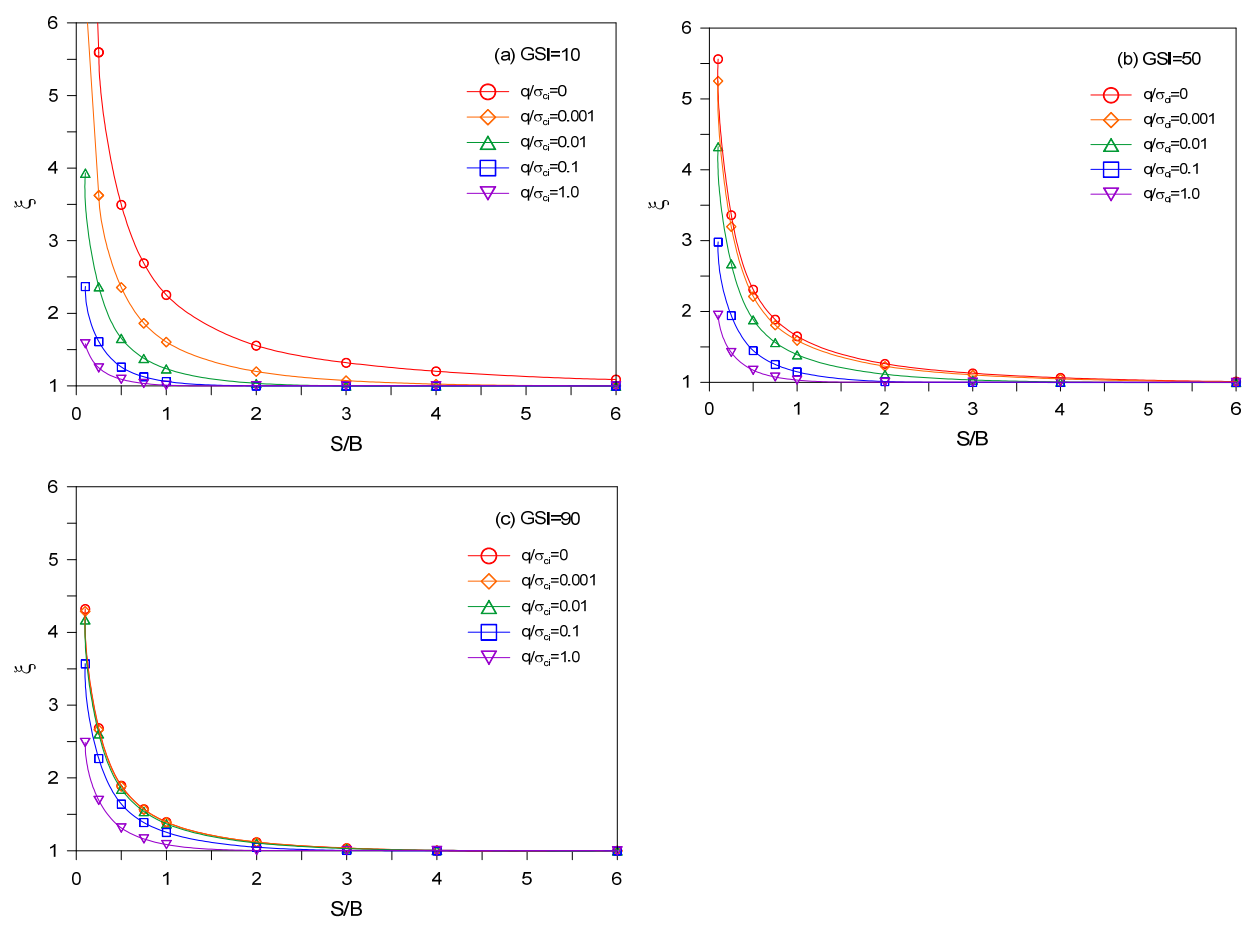

Figure 10. Variation of $\xi$ with $S / B$ and $q / \sigma_{c i}$ for $m_{i}=10, D=0$ and $\sigma_{c i} / \gamma B=\infty$ : (a) $G S I=10$; (b) $G S I=50$; and (c) $G S I=90$.

The variation of the efficiency factor $\xi$ for different combinations of $S / B$ and $G S I=10$, 90 for smooth and rough bases footings are shown in Figure 11 for the case of $D=0$, $\sigma_{c i} / \gamma B=$ infinite, $q / \sigma_{c i}=0$ and $m_{i}=7,15$, and 25 . Figure 11 shows that rough bases always maintain $\xi$ value greater than smooth bases. It can be seen that the varies in $\xi$ values due to roughness becomes smaller as GSI increases and vice versa increases as $m_{i}$ increases. However, it should be noted that $m_{i}$ has a small effect on the $\xi$ value and that GSI is significant.

Figure 12 shows the failure mechanism of the smooth and rough base multiple footings on the rock masses for different adjacent spacing ratios $S / B$ with $G S I=30, m_{i}=10, D=0$, $\sigma_{c i} / \gamma B=$ infinite and $q / \sigma_{c i}=0$. Figure 12 shows that unlike isolated footings, the failure mechanism of multiple footings does not lead to surface and is formed below the surface. As the $S / B$ of multiple footing increases, the failure mechanism of multiple footings changes close to failure mechanism of independent foundations. In the case of $S / B=2$, adjacent effects are expressed between the spacing of multiple footing and failure mechanisms are formed at relatively low depths. These effects can be seen to become decreases as $S / B$ increases. For rough bases, failure mechanism of multiple footing is formed in the external rather than center of the footing. On the other hand, for smooth bases, it should be noted that failure mechanism of multiple footings is formed simultaneously at center of footing and at the external. 

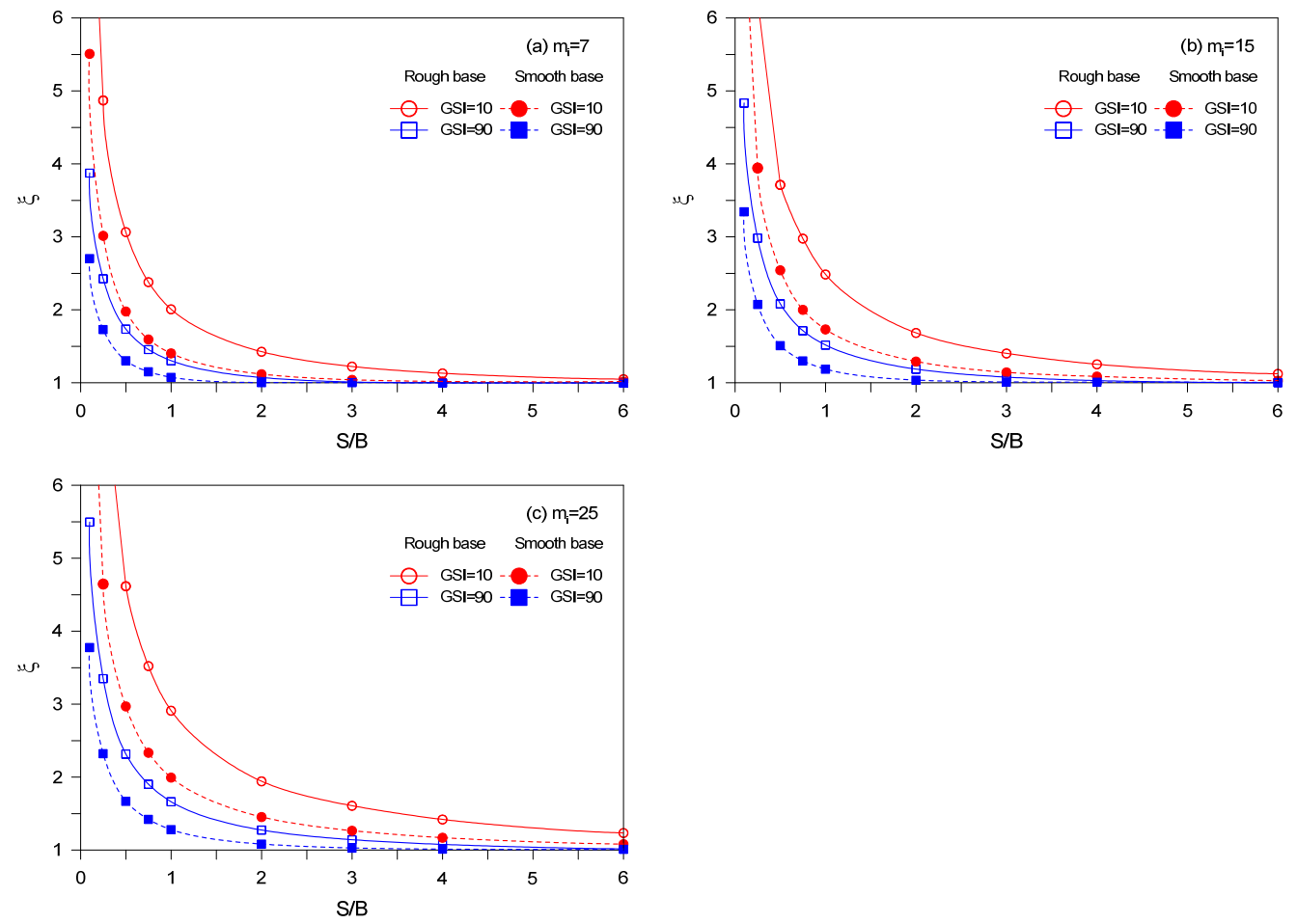

Figure 11. Variation of $\xi$ with $S / B$ and $G S I=10$ and 90 for rough and smooth bases footings with $D=0, \sigma_{c i} / \gamma B=\infty, q / \sigma_{c i}=0:(\mathbf{a}) m_{i}=7 ;$ (b) $m_{i}=15$; and (c) $m_{i}=25$.
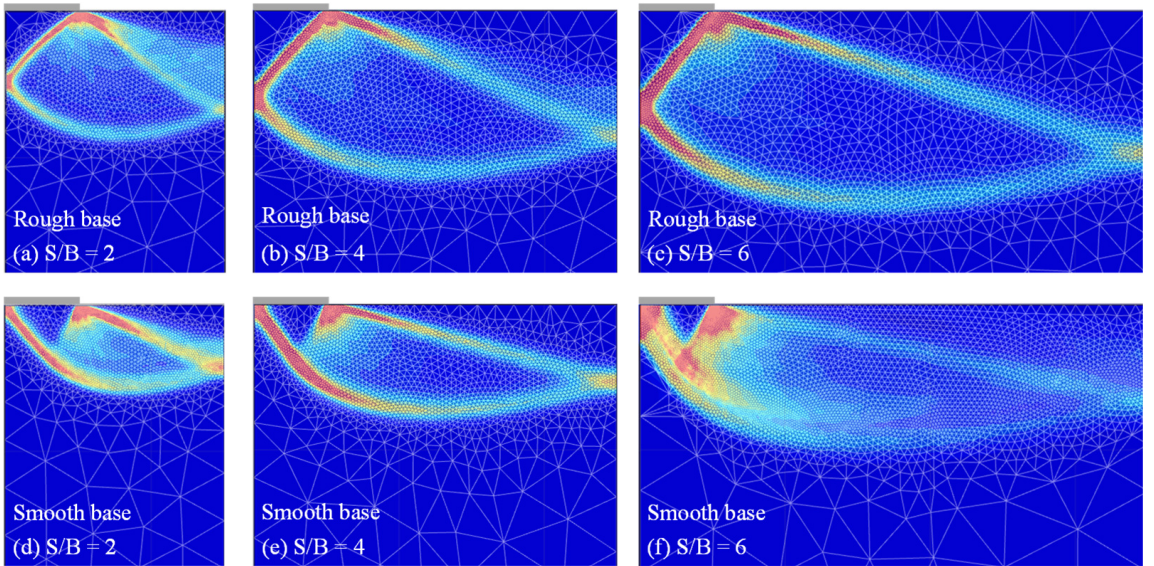

Figure 12. Failure mechanisms of multiple strip footings for $G S I=30, m_{i}=10, D=0, \sigma_{c i} / \gamma B=\infty$ and $q / \sigma_{c i}=0$ with different combinations of $S / B$ and base roughness: smooth base with (a) $S / B=2$; (b) $S / B=4$; and (c) $S / B=6$; rough base with (d) $S / B=2$; (e) $S / B=4$; and (f) $S / B=6$.

\section{Conclusions}

Advances in the use of numerical methods in rock engineering have been achieved, especially for continuum approaches for comprehensive constitutive models for rock fracture system. By means of the finite element limit analysis, the vertical bearing capacity of equally spaced multiple strip footings resting on rock mass is investigated. The rock mass is modeled by the modified Hoek-Brown failure criterion. Consideration is given to the effects of footing interference, Hoek-Brown parameters, surface surcharge, and footing roughness. The results are presented as efficiency factor $\xi$ in graphical form and failure mechanisms of multiple strip footings are discussed. The following conclusions can be drawn from the present study. 
As the spacing between the multiple footings decreases, the value of $\xi$ increases continuously and reach infinity at zero spacing. This indicates that the bearing capacity of an interfering footing with a given width is always greater than that of a single isolated footing with the same width. The effect of footings interference is found to be more significant for the lower values of GSI and $D$ and the higher value of $m_{i}$ and $\sigma_{\mathrm{ci}} / \gamma B$. An increase in surface surcharge leads to a decrease in $\xi$ and its trend is predominant for smaller GSI. The value of $\xi$ for rough footings is higher than smooth footings and the effect of the interference on the bearing capacity for rough base is greater than that for smooth base. The maximum spacing for which the nearby footings influence each other is determined and the closed-form expression is proposed. The zone of failure mechanism decreases dramatically for the interfering footings, implying a significant interaction between the adjacent footing and hence an increase in the bearing capacity of individual footings.

Author Contributions: Writing—original draft preparation, B.S.K. and J.K.L. All authors have read and agreed to the published version of the manuscript.

Funding: This research received no external funding.

Institutional Review Board Statement: The study did not require any ethical approval.

Informed Consent Statement: Not applicable.

Data Availability Statement: No applicable.

Acknowledgments: The authors acknowledge support in this research for the National Research Foundation of Korea (NRF) (Grant No. NRF-2020R1C1C1005374).

Conflicts of Interest: The authors declare no conflict of interest.

\section{References}

1. Brady, D.H.G.; Brown, E.T. Rock Mechanics for Underground Mining, 3rd ed.; Springer: Dordrecht, The Netherlands, 2004.

2. Singh, B.; Goel, R.K. Engineering Rock Mass Classification: Tunneling, Foundations, and Landslides; Elsevier: Oxford, MS, USA, 2011.

3. Zhang, L. Engineering Properties of Rocks, 2nd ed.; Elsevier: Oxford, MS, USA, 2016.

4. Stuart, J.G. Interference between foundations with special reference to surface footings in sand. Geotechnique 1962, 12, 15-22. [CrossRef]

5. Das, B.M.; Larbi-Cherif, S. Bearing capacity of closed-spaced strip foundations. Transp. Res. Rec. 1983, 945, 37-39.

6. Bransby, M.F.; Brown, M.J.; Knappett, J.A.; Hudacsek, P. The vertical capacity of grillage foundations. Geotechnique 2012, 62, 201-211. [CrossRef]

7. Graham, J.; Raymond, G.P.; Suppiah, A. Bearing capacity of three closely-spaced footings on sand. Geotechnique 1984, 34, 173-182. [CrossRef]

8. Kumar, J.; Bhoi, M.K. Interference of multiple strip footings on sand using small scale model tests. Geotech. Geol. Eng. 2008, 26, 469-477. [CrossRef]

9. Lee, J.; Eun, J. Estimation of bearing capacity for multiple footings in sand. Comput. Geotech. 2009, 36, 1000-1008. [CrossRef]

10. Raj, D.; Singh, Y.; Kaynia, A.M. Behavior of slopes under multiple adjacent footings and buildings. Int. J. GeoMech. 2018, 18, 04018062. [CrossRef]

11. Zidan, A.F.; Mohamed, M. Numerical analysis of bearing capacity of multiple strip footing on unreinforced and reinforced sand beds. SN Appl. Sci. 2019, 1, 1499. [CrossRef]

12. Kumar, J.; Bhattacharya, P. Bearing capacity of interfering multiple strip footings by using lower bound finite elements limit analysis. Comput. Geotech. 2010, 37, 731-736. [CrossRef]

13. Kouzer, K.M.; Kumar, J. Ultimate bearing capacity of equally spaced multiple strip footings on cohesionless soils without surcharge. Int. J. Numer. Anal. Methods GeoMech. 2008, 32, 1417-1426. [CrossRef]

14. Yang, F.; Zheng, X.; Sun, X.; Zhao, L. Upper-bound analysis of $\mathrm{N}_{\gamma}$ and failure mechanisms of multiple equally spaced strip footings. Int. J. GeoMech. 2017, 17, 06017016. [CrossRef]

15. Jiang, J.C.; Baker, R.; Yamagami, T. The effect of strength envelope nonlinearity on slope stability computations. Can. Geotech. J. 2003, 40, 308-325. [CrossRef]

16. Yang, X.; Yin, J. Upper bound solution for ultimate bearing capacity with a modified Hoek-Brown failure criterion. Int. J. Rock Mech. Min. Sci. 2005, 42, 550-560. [CrossRef]

17. Hoek, E.; Brown, E.T. The Hoek-Brown failure criterion and GSI-2018 edition. J. Rock Mech. Geotech. Eng. 2019, 11, 445-463. [CrossRef]

18. Javid, A.H.; Fahimifar, A.; Imani, M. Numerical investigation on the bearing capacity of two interfering strip footings resting on a rock mass. Comput. Geotech. 2015, 69, 514-528. [CrossRef] 
19. Shamloo, S.; Imani, M. Upper bound solution for the bearing capacity of two adjacent footings on rock masses. Comput. Geotech. 2021, 129, 103855. [CrossRef]

20. Hoek, E.; Carranza-Torres, C.; Corkum, B. Hoek-Brown failure criterion-2002 edition. Proc. NARMS-Tac 2002, 1, $267-273$.

21. Marinos, V.; Marinos, P.; Hoek, E. The geological strength index: Applications and limitations. Bull. Eng. Geol. Environ. 2005, 64, 55-65. [CrossRef]

22. Clausen, J. Bearing capacity of circular footings on Hoek-Brown material. Int. J. Rock Mech. Min. Sci. 2013, 57, 34-41. [CrossRef]

23. Hoek, E. Estimating Mohr-Coulomb friction and cohesion values from the Hoek-Brown failure criterion. Int. J. Rock Mech. Min. Sci. 1990, 27, 227-229. [CrossRef]

24. Merifield, R.S.; Lyamin, A.V.; Sloan, S.W. Limit analysis solutions for the bearing capacity of rock masses using the generalized Hoek-Brown criterion. Int. J. Rock Mech. Min. Sci. 2006, 43, 920-937. [CrossRef]

25. Keshavarz, A.; Kumar, J. Bearing capacity of foundations on rock mass using the method of characteristics. Int. J. Numer. Anal. Methods GeoMech. 2017, 42, 542-557. [CrossRef]

26. Sloan, S.W. Geotechnical stability analysis. Geotechnique 2013, 63, 531-572. [CrossRef]

27. Krabbenhoft, K.; Lyamin, A.; Krabbenhoft, J. Optum Computational Engineering (Optum G2). 2015. Available online: http: //www.optumce.com (accessed on 31 December 2021).

28. Serrano, A.; Olalla, C.; Gonzalez, J. Ultimate bearing capacity of rock masses based on the modified Hoek-Brown criterion. Int. J. Rock Mech. Min. Sci. 2000, 37, 1013-1018. [CrossRef]

29. Chakraborty, M.; Kumar, J. Bearing capacity of circular footings over rock mass be using axisymmetric quasi lower bound finite element limit analysis. Comput. Geotech. 2015, 70, 138-149. [CrossRef] 